\title{
Has Patriarchy been Stealing the Feminists' Clothes? Conflict-related Sexual Violence and UN Security Council Resolutions
}

\section{Chris Dolan*}

\begin{abstract}
The UN Security Council Resolution (UNSCR) 2106, in June 2013, and the declaration on preventing sexual violence in conflict adopted by $\mathrm{G} 8$ in London, in April 2013, signal a possible paradigm shift in how the international community can do 'gender', particularly in the arena of conflict-related sexual violence. Whilst UNSCR 1325 and its successors succeeded in drawing greater attention and funding to the particular needs of some women, they failed in comprehensively responding to the phenomenon of conflictrelated sexual violence. This is largely due to a systematic reluctance to confront the reality of conflictrelated sexual violence against men and boys, coupled with an active complicity in silencing that reality in what effectively reverted to a patriarchal discourse dressed up in feminist clothing. $A$ new and unashamedly gender-inclusive resolution is required if gender-based violence (GBV) interventions are to be released from the stifling grip of a patriarchal mode of 'doing gender'.
\end{abstract}

\section{Introduction}

The United Nations' Security Council Resolution (UNSCR) 2106 of 24 June 2013 (UN 2013), and the declaration on preventing sexual violence in conflict adopted by G8 foreign ministers in London just two months earlier on 11 April (G8 2013), signal an important paradigm shift in terms of how the international community does 'gender', particularly in the arena of conflictrelated sexual violence. For the first time a UNSCR within the Women, Peace and Security architecture acknowledged a place for men and boys in the discussion:
'sexual violence in armed conflict and post conflict situations disproportionately affects women and girls, as well as groups that are particularly vulnerable or may be specifically targeted, while also affecting men and boys and those secondarily traumatized as forced witnesses of sexual violence against family members' [emphasis added] (UN 2013).

While the acknowledgement of men and boys is rather tentative, and can be interpreted as trying to minimise the significance of sexual violence against them, it nonetheless stands in stark contrast to the complete silence of the preceding 13 years of such resolutions, from UNSCR 1325 onwards. The G8 (2013) declaration was, at least linguistically, considerably more robust in breaking with entrenched policy and practice by calling for comprehensive services to victims, 'be they women, girls, men or boys' (ibid.: 2).

This robust call for non-discriminatory services by the G8, and the simple statement from the UN Security Council that followed it, do, I would suggest, open up the possibility of more empirically grounded, more nuanced, and more inclusive understandings and approaches to gendered power and its manifestations in conflict situations. Although it will take time for the shift in paradigm to be reflected in the policies and practices of multilateral institutions, governments and civil society actors, there is now at least some prospect that the millions of male victims of sexual violence who currently enjoy little or no recourse to support or assistance, will in future be able to access appropriate services, and that this 
in turn will help to interrupt cycles of violence, whether at the domestic, national or international level. When this happens, it will be possible to look back and see more clearly how, paradoxically, from UNSGR 1325 to 1889 (UN 2009), Patriarchy in the form of the Security Council had effectively stolen the feminist's clothes. It will become evident that many years of important feminist activism were effectively co-opted, and that the emancipatory potential of a true gender analysis was lost to a re-essentialising and patriarchal gender binary in which women were portrayed as weak (victims) and men as strong (perpetrators).

\section{How patriarchy stole the clothes of feminism}

As the elision and substitution of one of the central pillars of patriarchy (women are weak, men are strong) with one of the core tenets and rallying calls of gender experts (women are victims, men are perpetrators) shows, much of patriarchy's successful cross-dressing has been by way of discursive sleight of hand. An analysis of key features of the discourse on conflict-related sexual violence suggests a number of key instances.

The first of these is the usual claim that 'women and girls/children are disproportionately/ primarily affected by sexual violence'. This goes hand-in-hand with the beliefs that sexual violence is always under-reported, and that it should always be assumed to be there in emergency settings. There is little critical reflection on the paradox that both these beliefs hold as true for men as they do for women, and in certain contexts even more so. Given the reality of under- or non-reporting by male victims, and the failure to document even some of those cases that are reported, ${ }^{1}$ how sure can we be that the claim of women and girls being primarily affected holds true in all situations?

Notwithstanding the fundamental fragility of this primary claim, it is the basis from which a number of other explicit and implicit assumptions flow; firstly, that if there are men and boy victims they are so few in numbers or minimal in proportion to the numbers of women and girls as to be not worth bothering with. Secondly, if the great majority of victims are female, the perpetrators must logically be all male. To a certain extent the latter inference also informs the drive to engage men - as latent or actual perpetrators - in efforts to prevent their own gender-based violence (GBV) against women.

A similar binary logic is implicit in the many statements to the effect that 'sexual violence undermines women's capacity to contribute meaningfully'. This is still the case in UNSCR 2106 which emphasises 'that acts of sexual violence in such situations not only severely impede the critical contributions of women to society, but also impede durable peace and security as well as sustainable development' (UN 2013). The failure to mention that men's capacity to contribute meaningfully is equally fundamentally undermined by sexual violence is a profound sin of omission insofar as it prevents closer scrutiny of what is needed to prevent or respond to such a loss of capacity.

In short, simplistic and stereotypical gender binaries, characterised by a unidirectional balance of power in favour of all men, to the disadvantage of all women, are continually re-inscribed. There is no acknowledged need to disaggregate the two parts of the equation, or to understand intersections with other characteristics of the person such as their race, class or ethnicity. These are only recognised where they create additional vulnerability for women; it is never acknowledged that these intersections may at times reduce some women's vulnerability to lower levels than that of some men. Consequently, a simple vision of every individual man having more power than all of womankind is sustained, a privileged victim status for women and girls is entrenched, and alternative narratives and realities are silenced.

A further interesting characteristic example of where a feminist position has been co-opted by patriarchal interests is in the use of the mantra that 'rape is about power, not sex' when discussing sexual violence in conflict. The statement should, if true, alert us to the possibility that the sex and sexuality of the victim of violence is secondary to the primary purpose of sexual violence in conflict, namely to change the power relationship between the perpetrator and the victim by leveraging highly patriarchal gender norms held by perpetrator and victim alike. On this reading of the purpose of sexual violence, men and boys are as likely as women (if not at times more so) to be the object of some forms of conflict-related sexual violence, 
for the feminisation of a man, to a perpetrator programmed by such a mindset, could be a greater achievement than the further abasement of an already subjugated woman. Strangely, this simple inference has not been reflected in the shape of interventions into the prevention of and response to sexual gender-based violence (SGBV).

There may also be a more subtle level of hidden inference here. The refusal to contemplate describing any intercourse in which unequal power is at play as 'sex' can be seen as a logical extension of the perspective that a woman has the right to full control over her body. This has the unfortunate side effect of closing down any discussion of how many people's sexuality actually is, as opposed to how it should be.

Furthermore, the assumption that rape is about power, when conjoined with the assumption that the important imbalance of power is between men and women, also does nothing to destabilise dearly-held assumptions that the only kind of rape is that of women by men. Not only does the stubborn silence about sex and sexuality to be found in most UN documents reflect a serious blind-spot to the fact that the homophobia, which is intrinsic to patriarchy, will inform the strategic use of sexual violence against men, and deepen its negative impact on the victims, it also blocks any challenge to the assumed heterosexual nature of acts of sexual violence. These are indeed missed opportunities to understand and prevent sexual violence.

The stubborn silence about sex and sexuality to be found in most UN documents blocks any challenge to the assumed heterosexual nature of acts of sexual violence. It is reminiscent of the stubborn refusal of many prison services to supply male inmates with condoms, in that it inverts cause and effect; the belief that sex can be taken out of sexual violence, is as mistaken as the belief of prison wardens that male prisoners will not have sex with one another if they are not given condoms.

While all of the above assumptions and assertions are generally claimed by gender technocrats to be feminist, this is only true to the extent that they recognise women's assumed disadvantage. At a much more fundamental level they perpetuate some of the core tenets of patriarchy: namely, they take male power as a given rather than as a social construct, and they refuse to consider what the reality of male vulnerability to sexual violence does to a simple model in which men are, per se, more powerful, and women are intrinsically vulnerable. As such, certain elements of feminist thought are to be found co-opted into the antifeminist backlash against serious attempts to deconstruct the social constructs underpinning patterns of oppression and exclusion.

One of the ironies of the manner in which discourses about sexual violence which are actually useful to patriarchy have been able to co-opt what were initially proudly feminist arguments, is the way in which gender 'experts' have knowingly or inadvertently been complicit in the process. As the discussion of the term 'disproportionately affected' has shown, language and imagery are used in ways which continually re-inscribe the very constructs that we should be deconstructing.

This extends to the legal frameworks with which sexual violence is supposed to be addressed. As Eriksson Baaz and Stern's (2013) analysis of the relationship between military structures and sexual violence in conflict shows, the reality on the ground is often very far from the highly idealised model of men in total control that underpins the theory of command responsibility. In short, the very language of command responsibility, as well as the legal processes that are set up on the basis of that language and accompanying set of assumptions, simultaneously re-inscribe ideals which a true gender and feminist analysis would necessarily interrogate, and, by institutionalising the divergence between what actually happened and the response to it, they almost guarantee the failure of any judicial remedies.

Another of the paradoxes about the discourse on sexual violence in conflict situations is that it is characterised by a number of intellectual doublestandards. This is particularly true of the fact that sexual violence is always under-reported; the fact that women under-report is seen as something that service providers should actively compensate for (the IASC guidelines on responding to GBV in emergency situations, for example, argue that: 'All humanitarian personnel should therefore assume and believe that GBV, and in particular sexual violence, is taking place and is a serious and lifethreatening protection issue, regardless of the presence or absence of concrete and reliable 
evidence' (2005: 2)), yet the lack of reporting by men and boys is often taken as sufficient confirmation that this area of sexual violence is of little concern. The basic insight that good interventions are those which are evidence-based, and the knowledge from all the sciences that the evidence base is only as good as the questions asked, are both blatantly ignored. Assertions such as 'sexual violence in armed conflict and postconflict situations disproportionately affects women and girls' should not pass muster, yet they are routinely taken as a sociological truth by the same stakeholders that themselves acknowledge that this particular phenomenon is routinely under-reported.

The Global Protection Cluster calls for nondiscrimination of survivors of sexual violence as a key principle for survivor-centred responses, yet it systematically excludes men and boys (let alone trans and gender non-conforming persons) from consideration. Consider a standard-setting policy document on which gender training instruments have been built, namely the 2005 Inter-Agency Standing Committee Guidelines on Responding to GBV in Emergency Settings (IASC 2005). The IASC guidelines are the outcome of a series of consultations and expert guidance, and are espoused by the major relevant UN institutions, as well as major international NGOs who partner with the UN. Not one of the references cited in the guidelines relates to men and boy victims. In the entire four modules of a UNFPA (2011) e-learning course derived from the IASG guidelines, there is not a single case study of a male victim, there are many images of women victims, but no image of a man (other than in the section discussing engaging men in prevention efforts), and when victims are discussed, the pronoun is always 'she'. Sexual exploitation is presented as something that only applies to women and children.

One of the fundamentals of non-discrimination is that being in a minority (i.e. lack of numbers) does not justify discrimination, yet the IASC (2005) guidelines and the UNFPA (2011) training modules do exactly that; they assert that men and boys are a minority, women and girls the majority, and then exclude the minority from any consideration whatsoever. The training modules thus, while urging the learner to not discriminate, themselves epitomise discrimination through the silencing of some categories of victims.

\section{Discussion}

UN Security Council Resolution 1325 (UN 2000) is widely seen as embodying the success of feminist activism, and in many senses it was. However, while 1325 and its successors (e.g. UN 2009) did succeed in drawing greater attention and funding to the particular needs of some women, they failed in the goal of comprehensively responding to and preventing the phenomenon of conflict-related sexual violence, largely, I would argue, due to a systematic reluctance to confront the reality of conflict-related sexual violence against men and boys, coupled with an active complicity in silencing that reality in what effectively reverted to a patriarchal discourse dressed up in feminist clothing. At a practical level this left countless male victims with no response to their suffering, despite the fact that this suffering intersects with and compounds that of their spouses, children, households, countries and society at large. At a conceptual level there was a refusal to contemplate what sexual violence against men implies for the simple binary model of male-female gender power around which the global gender industry of the nineties and noughties had been built.

UNSGR 2106 (UN 2013) represents a major advance in thinking by stakeholders operating within and around the UN. Given that any such resolution is the outcome of multiple discussions, consultations, inputs, and political manoeuvring, and therefore tends to reflect the lowest common denominator rather than the most progressive thinking, the broadening of recognised categories of victims of conflict-related sexual violence to include men and boys and those secondarily traumatised must be viewed as a critical moment in the history of policy and practice relating to SGBV in conflict situations, and the moment at which a window for comprehensive and gender-inclusive response and prevention finally began to open.

While the cracks in patriarchy's feminist disguises are beginning to show, a new, explicitly and unashamedly gender-inclusive Security Council resolution is required if GBV interventions are to be released from the conceptually and practically stifling grip of a patriarchal mode of 'doing gender'. An inclusive resolution can draw on the G8 (2013) declaration. Such a resolution would be truly feminist in that it would promote not a simple changing of the 
male guard with a female one, but a world in which guards are not needed because the binary opposition of insiders and outsiders has been exposed for what it is, namely an instrument of

\section{Notes}

* Director, Refugee Law Project, School of Law, Makerere University, dir@refugeelawproject.org.

1 This observation stems from refugee clients presenting at the Refugee Law Project after having been ridiculed by police officers to whom they have attempted to report their situation.

\section{References}

Eriksson Baaz, M. and Stern, M. (2013) Sexual Violence as a Weapon of War? Perceptions, Prescriptions, Problems in the Congo and Beyond, London and New York: Zed Books

G8 (2013) Declaration on Preventing Sexual Violence in Conflict: Adopted in London on 11 April 2013, London: Foreign and Commonwealth Office, www.gov.uk/government/uploads/system/ uploads/attachment_data/file/185008/G8 PSVI_Declaration_-_FINAL.pdf (accessed 22 November 2013)

Henry, S.; Rizvi, F. and Tchoukleva, I. (2013) 'Promoting Accountability for Conflict-related Sexual Violence against Men: A Comparative Legal Analysis of International and Domestic Laws Relating to IDP and Refugee Men in Uganda', Refugee Law Project Working Paper 24, www.refugeelawproject.org/working_papers/ RLP.WP24.pdf (accessed 22 November 2013) IASC (2005) Guidelines for Gender-Based Violence Interventions in Humanitarian Settings: Focusing on political, social and economic manipulation to the advantage of certain institutions and to the disadvantage of ordinary citizens.

2 In one recent study conducted by the Refugee Law Project on access to justice for survivors of sexual violence, the lack of police statistics on sexual violence against men and boys was taken by the sponsors of the research (a UN body) as evidence that there is no such violence. The study remains unpublished to date as a result.

Prevention of and Response to Sexual Violence in Emergencies (Field Test Version), Geneva: Inter-Agency Standing Committee, www.globalprotectioncluster.org/_assets/files/ tools_and_guidance/IASG_GenderBased Violence_HumanitarianSettings_2005_EN.pdf (accessed 22 November 2013)

UNFPA (2011) Managing Gender-Based Violence Programmes in Emergencies, United Nations' Population Fund, https://extranet.unfpa.org/ Apps/GBVinEmergencies/index.html (accessed 22 November 2013)

UN Security Council (2013) Resolution 2106: Women Peace and Security, http://unscr.com/en/ resolutions/2106 (accessed 22 November 2013)

UN Security Council (2009) Resolution 1889: Women and Peace and Security, http://unscr.com/en/ resolutions/1889 (accessed 22 November 2013)

UN Security Council (2000) Resolution 1325: Women and Peace and Security, http://unscr.com/en/ resolutions/1325 (accessed 22 November 2013) 